\title{
СЕРГЕЙ НИКОЛАЕВ
}

0000-0002-0900-9226

Институт русской литературы

(Пушкинский Дом)

Российской Академии наук

Отдел русской литературы XVIII века

199034 Санкт-Петербург

наб. Макарова, д. 4

sergej_nikolaev2@mail.ru

\section{«К СТИХАМ СВЕРБЕЖ ВЕЛИКИЙ»: ПОЭТЫ ХVІІІ ВЕКА О НЕУЕМНОЙ СТРАСТИ К СОЧИНИТЕЛЬСТВУ}

\author{
CRAVING FOR POETRY: $18^{\mathrm{TH}}$-CENTURY POETS' \\ VIEWS ON THE UNCONTROLLABLE \\ DESIRE TO WRITE POETRY
}

C самого начала XVIII в. русские поэты заговорили о неуемной страсти к сочинению стихов, как своей, так и других поэтов. При этом собственная «прегнусная охота» к сочинению стихов добродушно оправдывалась, а вот чужая точно такая же страсть довольно зло высмеивалась и осуждалась: «Все предавались стихотворству до тошноты», писал Феофан Прокопович. Для осуждения этой страсти были все основания: многописание приводило к ухудшению стиля и деградации литературного мастерства, дилетантизму и падению престижа литературной работы. Еще одним следствием стало появление графомании, которая также подвергалась осуждению в литературных полемиках. В статье на многочисленных примерах показано, что вся эта проблематика связана со становлением литературной культуры Нового времени, с изменением структуры литературного быта и формированием образа писателя, который в основных своих чертах сохранился до нашего времени.

Ключевые слова: литературная культура, графомания, дилетантизм, образ автора, causa scribendi.

The penchant for writing poetry became a prominent discussion topic among Russian poets at the very beginning of the $18^{\text {th }}$ century. While poets would usually exonerate themselves of their own "wretched inclination" to versify profusely, they would ridicule and judge similar proclivities shown by fellow poets: as Feofan Prokopovich put it, Omnes ad nauseam versificari occeperant ("everyone was composing verses in the most annoying way"). This kind of criticism was not unfounded: prolific writing led to a deterioration in style, loss of literary craft, dilettantism, and 
an overall decline in the prestige of the profession. Another consequence was the rise of graphomania that was likewise found reprehensible in literary polemics. Using many case studies, the author of the paper argues that these debates were closely tied to the formation of the literary culture of Modern Times, to changes in daily literary life and to the development of the image of a writer which for the most part would remain unchanged until the present.

Keywords: literary culture, dilettantism, graphomania, image of the author, causa scribendi.

Тайны творчества издавна занимали как самих писателей, так и исследователей - откуда берется и что такое вдохновение? Что такое дарование? Как писатель осознает свое призвание и что такое вообще - быть автором? Как овладеть тайнами ремесла? В чем заключается оригинальность творчества? Вопросов этих много, и ответы на них искали не только литературоведы, но и представители других наук - психологи, историки, социологи, медики и др. Однозначных и убедительных ответов до сих пор не найдено и вряд ли они отыщутся и всех удовлетворят. Однако все это не останавливает исследователей от новых и бесчисленных попыток заглянуть в «лабораторию писателя» и наконец-то отыскать формулу «алхимии слова». Все эти вопросы относятся не только к истории литературы, они исключительно актуальны и сейчас, достаточно вспомнить недавние присуждения Нобелевской премии по литературе Светлане Алексиевич или Бобу Дилану. Присуждение этих наград вызвало неоднозначные реакции как раз в писательской среде. Списывать резкость этих суждений только на авторскую ревность или попросту зависть было бы неверно. Писателей даже можно понять: в этих присуждениях они увидели покушение на давно устоявшиеся представления о том, что такое «литература» и кто является именно «писателем». Актуальность и одновременно неразрешимость этих вопросов объясняется, в частности, тем, что литература - это живой, вечно изменяющийся процесс. Не могу не привести глубокое суждение М. И. СтеблинаКаменского из его статьи Заметки о становлении литературы (к истории художественного вымысла):

По существу история литературы - это и есть история ее становления. Ошибочно думать, что ее становление - это процесс, который завершился где-то в доисторическую эпоху и о котором можно себе составить представление только по материалам о современно культурно отсталых народах. Процесс этот охватывает не только все древние и средневековые литературы, но продолжался и в новое время и, по всей вероятности, еще не закончился ${ }^{1}$.

${ }^{1}$ И. М. Стеблин-Каменский, Труды по филологии, Санкт-Петербург: Филологический факультет Санкт-Петербургского государственного университета 2003, с. 557. 
«Неуемная страсть к сочинительству» - это достаточно узкая тема, к тому же она теснейшим образом связана с другими родственными ей понятиями - вдохновение, творческий процесс, графомания, социальная роль и социальная маска поэта. Как раз в XVIII веке эти категории входили в русскую литературную культуру. Конечно, в этом столетии разработка этих понятий не завершилась, что замечательно описал А. С. Пушкин в незавершенной повести Египетские ночи (1834), затронув две важнейшие проблемы: какова природа вдохновения и какова социальная роль автора:

Жизнь его могла быть очень приятна; но он имел несчастие писать и печатать стихи. В журналах звали его поэтом, а в лакейских сочинителем. [...] Однако ж он был поэт, и страсть его была неодолима: когда находила на него такая дрянь (так называл он вдохновение), Чарский запирался в своем кабинете и писал с утра до поздней ночи. Он признавался искренним своим друзьям, что только тогда и знал истинное счастие ${ }^{2}$.

После первой импровизации итальянца Чарский был поражен:

Итак, для вас не существует ни труда, ни охлаждения, ни этого беспокойства, которое предшествует вдохновению?.. Удивительно, удивительно!..

Импровизатор отвечал:

- Всякой талант неизъясним. Каким образом ваятель в куске каррарского мрамора видит сокрытого Юпитера и выводит его на свет, резцом и молотом раздробляя его оболочку? Почему мысль из головы поэта выходит уже вооруженная четырьмя рифмами, размеренная стройными однообразными стопами $?^{3}$

Здесь особенно важны словосочетания «неодолимая страсть» и «беспокойство, которое предшествует вдохновению», т. е. тяга и страсть к сочинению стихов. Место поэта в русской социальной структуре литературы Чарский (т. е. Пушкин) в данном случае искажает:

Вы ошибаетесь, Signor, - прервал его Чарский. - Звание поэтов у нас не существует. Наши поэты не пользуются покровительством господ; наши поэты сами господа, и если наши меценаты (черт их побери!) этого не знают, то тем хуже для них. У нас нет оборванных аббатов, которых музыкант брал бы с улицы для сочинения libretto. У нас поэты не ходят пешком из дому в дом, выпрашивая себе вспоможения ${ }^{4}$.

${ }^{2}$ А. С. Пушкин, Полное собрание сочинений: в 10-ти томах, Ленинград: «Наука» 1978, T. 6 , c. $244,245$.

${ }^{3}$ Там же, с. 251.

${ }^{4}$ Там же, с. 247. 
А вот страсть к писанию стихов появилась в европейской литературе задолго до XVIII века. Хрестоматийными и даже вошедшими во фразеологию стали слова Ювенала «сасоethes scribendi» из 7-й сатиры:

Мы как в петле привычки к тщеславному делу; свободы

Нам не дано, а зараза писать не у всех излечима.

Болью души она держит людей и в них матереет ${ }^{5}$.

Позднее Гете назвал этот художественный позыв «Lust zu fabulieren» («страсть к сочинительству»).

Появление и проявления этой страсти в самых разнообразных авторских признаниях русских поэтов XVIII в. многочисленны. И эта страсть не зависит от социального положения автора. Князь А. Д. Кантемир в 4-й сатире (первой редакции) признается:

А не писать мне нельзя: не могу стерпети

Богат, нищ, весел, скорбен - буду стихи ткати'.

Василий Лёвшин в обширном стихотворении Сочинитель к перу своему, помещенном в его Русских сказках (1780), пишет:

Тебя, мое перо, золотом обложат,

А мне писати страсть этим приумножат.

Хвалы хоть за ноли не можем уж мы брать,

Но страсть к писанию в ком удобно удержать?

Н. П. Николев в комедии Самолюбивый стихотвореи (1775) приводит слова, поставленные в название статьи: «к стихам свербеж великий» и тут же добавляет «к кропанию стихов прегнусная охота» ${ }^{8}$.

Схожие стенания мы найдем и в поэзии начала XIX в. С. Н. Марин во 2-й сатире сетует:

${ }^{5}$ Римская сатира. Пер. с лат., Москва: «Художественная литература» 1989, с. 286.

${ }^{6}$ А. Кантемир, Собрание стихотворений, Ленинград: «Советский писатель» 1956, c. 391,392 .

${ }^{7}$ В. А. Лёвшин, Русские сказки, Москва 1780, ч. 4, с. $81,83$.

${ }^{8}$ См.: Стихотворная комедия, комедия, комическая опера, водевиль конца XVIII - начала ХІХ века, Ленинград: «Советский писатель» 1990, т. 1, с. 277. 
И сколько наконец ни мучусь, ни терзаюсь, А с рифмою моей никак не повстречаюсь.

Досадуя решусь, себя чтоб не томить, Стихи и рифмы все навеки позабыть; Несчастну страсть мою к писанью проклинаю. Ах! тщетно удержать себя предпринимаю! И, муз всех разругав и Феба разбраня, Приходит бешенство маранья на меня; Когда ж надежды нет, скажи мне без притворства, Как мне избавиться от страсти стихотворства?

О своей страсти к писанию («ma fureur d'écrire») не один раз пишет в своих письмах и статьях замечательный поэт М. Н. Муравье ${ }^{10}$. А представитель другого сословия В. Г. Рубан в своем журнале «Ни то, ни сио» (1769) поминает «зуд, побуждающий к сочинениям» ${ }^{11}$ и т. д. Число примеров можно умножить.

На упомянутом европейском фоне в этой страсти нет ничего необычного или исключительного. Но вот в контексте истории русской литературы появление этой «охоты», «страсти», «зуда», «свербежа» очень показательно. От XVII в., особенно от второй его половины до нас дошло значительное число авторских произведений, в том числе стихотворных. Авторская топика древнерусской литературы уже изучена достаточно внимательно, но никаких упоминаний о «страсти писать» или о «свербеже» нет. И этому есть объяснения. Старорусский книжник духовного звания писал по обету или прямо «по понуждению» - формально с точки зрения авторской топики это обстояло так и для протопопа Аввакума. Переводчик Посольского приказа переводил или сочинял по служебному долгу - все они не нуждались в объяснении своих занятий литературой, а если «зуд» и появлялся (что вообще-то не исключено), то они его стыдились или стеснялись. Например, Симеон Полоцкий был очень плодовитым автором. Сильвестр Медведев, который с лета 1667 г. жил с ним в соседней келье, так описывал последние дни и литературные труды своего учителя:

Кътому присно прилежал чтению и писанию. На всякий же день име залог писати в полдесть по полутетрати, а писание его бе зело мелко и уписисто. И пребывая на Москве 16 лет, написа своею рукою разных книг по исчислению прологов с десять или и вящше. О нихже аз Богу мне вспомогающу тщуся, да соберутся все в книги и миру да явятся ${ }^{12}$.

\footnotetext{
${ }^{9}$ Поэты-сатирики конща XVIII-начала XIX в., Ленинград: «Советский писатель» 1959, c. $190-192$.

${ }^{10}$ См.: Письма русских писателей ХVIII в., Ленинград: «Наука» 1980, с. 303-304.

${ }^{11}$ См.: «Ни то, ни сио» 1769 , лист 20, 11 июля, с. 157.

${ }^{12}$ Simeon Polockij, Vertograd mnogocvětnyj, Vol. 3: «Prav nikto že» - «Epitafion» Simeonu, ред. Anthony Hippisley, Lydia I. Sazonova, Köln; Weimar; Wien: Böhlau Verlag 2000, с. 630.
} 
И это было не графоманство, это была творческая просветительская установка барочного полигистора.

Но на рубеже XVII-XVIII веков произошел культурный переворот, с литературой напрямую никак не связанный. Процесс столкновения и смены культурных ценностей, начавшийся еще до реформ Петра I, привел уже в первой четверти XVIII в. к важному изменению в структуре литературной культуры: «каждый мог писать невозбранно - в качестве частного человека, вне и помимо служебных обязанностей. Писатель стал частным человеком, частный человек стал писателем» ${ }^{13}$. Сказано афористично, но очень точно. И вот в этой новой атмосфере и обстановке «зуд» и «свербеж» сразу дали себя знать. В одном из частных писем Феофан Прокопович писал (на латинском языке) о стихотворстве в киевской коллегии: «Omnes ad nauseam versificari occeperant» («Все предавались стихотворству до тошноты») $)^{14}$. Страсть к писанию принимала иногда почти болезненные формы. В конце 1680-х гг. дьякон Петр Артемьев посетил Рим, а в 1691 г. вернулся в Москву. В его проповедях были усмотрены прокатолические взгляды. Он был отрешен от службы, расстрижен и сослан в монастырь в Холмогоры, где вскоре и умер в 1700 г. Будучи уже в заточении в холмогорской тюрьме, не имея бумаги, он записывал свои стихи на ветхозаветные и евангельские темы на окнах и оконных рамах - столь велика была тяга к сочинительству: «А в тюрьме у него во окнах, по обоконьям, по дереву писано было и после его усмотрено» ${ }^{15}$. Эти стихи сохранились и позднее были опубликованы.

А. П. Сумароков в 1774 г. писал: «... зараза пиитичества весь российский Парнас невежественно охватила, а я истребления оному более предвидети не могу, жалея, что прекрасный наш язык гибнет» ${ }^{16}$. В 1772 г. неизвестный прислал письмо в журнал Н. И. Новикова «Живописец» и просил совета: «Что мне делать? Хочется писать, да не знаю, за что приняться: кажется мне, что мог бы я написать все, но однако ж по сие время не написал еще ничего» ${ }^{17}$.

Это были следствия происходящих в XVIII в. культурных перемен. Каждый мог свободно писать все что угодно. Тредиаковский отметил не без горечи:

${ }^{13}$ А. М. Панченко, О смене писательского типа в петровскую эпоху, [в:] Проблемы литературного развития в России первой трети ХVIII века, Ленинград: «Наука» 1974, с. 125 (XVIII век. Сб. 9).

${ }^{14}$ Epistolae illustrissimi ac reverendissimi Theophanis Prokopowicz variis temporibus et ad varios amicos datae nunc primum in usum corpus collectae et suo ordine digestae, [Mosquae]: Typis Universitatis Caesareae Mosquensis 1776, c. 58.

${ }^{15}$ А. А. Титов, Летопись Двинская, Москва 1889, с. 108.

${ }^{16}$ А. П. Сумароков, Полное собрание всех сочинений, (изд. 2) Москва 1787, ч. 9, с. 220.

${ }^{17}$ Сатирические журналь Н. И. Новикова, Москва-Ленинград: Издательство Академии наук СССР 1951, с. 357. 
Прежде стихи были нужное и полезное дело, а ныне утешная и веселая забава, да к тому ж плод богатого мечтания к заслужению не того вещественного награждения, которое есть нужно к препровождению жизни, но такова воздаяния, кое часто есть пустая и скоро забываемая похвала и слава ${ }^{18}$.

Авторское тщеславие стало расти не по дням, а по часам и стало предметом многочисленных сатирических произведений. Но более существенными и ощутимыми были другие последствия: деградация художественного стиля и слога, а также графомания. Уже Димитрий Ростовский и Антиох Кантемир выносят строгий приговор многописанию Иоанна Максимовича - наступала новая эпоха с новыми оценками и новыми эстетическими ценностями. А вот «к стихам свербеж великий» навсегда вошел в отечественную авторскую топику. Столь распространенный в литературе романтизма тип «неистового стихотворца» появился благодаря этому зуду ${ }^{19}$. Можно по-разному относиться к самой формулировке «к стихам свербеж великий», но она стала чертой литературной культуры и типа писателя нового времени.

В заключение продолжу цитату из сатиры Ювенала. Сразу после «зараза писать» он пишет:

\footnotetext{
Лишь выходящий из ряда поэт, особенной крови,

Что не привык повторять приведенное, что не чеканит

Пошлых стихов одинакой для всех разменной монетой, -

Этот поэт - я не знаю его, а чувствую только -

Создан духом превыше забот, без горечи вовсе;

Он стремится в леса и жадно пьет Аонидин

Ключ вдохновенья ${ }^{20}$.
}

Вот такому пониманию «избранного поэта» была суждена долгая жизнь и в русской литературе, особенно в эпоху романтизма.

\section{References}

Epistolae illustrissimi ac reverendissimi Theophanis Prokopowicz variis temporibus et ad varios amicos datae nunc primum in usum corpus collectae et suo ordine digestae. [Mosquae]: Typis Universitatis Caesareae Mosquensis, 1776.

\footnotetext{
${ }^{18}$ В. К. Тредиаковский, Письмо к приятелю о нынешней пользе гражданству от поэзии, [в:] он же, Сочинения, Санкт-Петербург 1849, т. 1, с. 206-207.

${ }^{19}$ См.: Н. Н. Мазур, Маска неистового стихотвориа в «Евгении Онегине»: полемические функиии, [в:] Пушкин и его современники: Сборник научных трудов, вып. 5 (44), Санкт-Петербург 2009, с. 141-208.

${ }^{20}$ Римская сатира..., с. 286.
} 
Kantemir, Antiokh. Sobranie stikhotvorenii. Leningrad: Sovetskii pisatel, 1956.

Levshin, Vasilii. Russkie skazki. Moskva, 1780: 4.

Mazur, Natalya. Maska neistovogo stikhotvortsa v "Evgenii Onegine": polemicheskie funktsii. In: Pushkin i ego sovremenniki: Sbornik nauchnykh trudov, No. 5 (44). Sankt-Peterburg, 2009: 14-208.

Ni to, ni sio (1769), list 20, 11 iyulya.

Panchenko, Aleksandr. O smene pisatelskogo tipa v petrovskuyu epokhu. In: Problemy literaturnogo razvitiya $v$ Rossii pervoi treti XVIII veka. Leningrad: Nauka, 1974: 112-128.

Pisma russkikh pisatelei XVIII v. Leningrad: Nauka, 1980.

Poety-satiriki kontsa XVIII - nachala XIX v. Leningrad: Sovetskii pisatel, 1959.

Pushkin, Aleksandr. Polnoe sobranie sochinenii: v 10-ti tomakh. Leningrad: Nauka, 1978: 6.

Rimskaya satira. Per. s lat. Moskva: Khudozhestvennaya literatura, 1989.

Satiricheskie zhurnaly N. I. Novikova. Moskva-Leningrad, 1951.

Simeon, Polockij. Vertograd mnogocvětnyj, Vol. 3: "Prav nikto že" - "Epitafion" Simeonu, ed. Anthony Hippisley and Lydia I. Sazonova. Köln; Weimar; Wien: Böhlau Verlag, 2000.

Steblin-Kamenskii, Ivan. Trudy po filologii. Sankt-Peterburg: Filologicheskii fakultet SanktPeterburgskogo gosudarstvennogo universiteta, 2003.

Stikhotvornaya komediya, komediya, komicheskaya opera, vodevil kontsa XVIII - nachala XIX veka. Leningrad: Sovetskii pisatel, 1990: 1.

Sumarokov, Aleksandr. Polnoe sobranie vsekh sochinenii. Moskva, 1787: 9.

Titov, Andrei. Letopis Dvinskaya. Moskva, 1889.

Trediakovskii, Vasilii. Pismo k priyatelyu o nyneshnei polze grazhdanstvu ot poezii. In: Sochineniya. Sankt-Peterburg, 1849: 1. 